\title{
Caracterização de genótipos de soja com resistência parcial à ferrugem da soja
}

Fernando Cezar Juliatti ${ }^{1,3} \mathbb{0}$; Ana Carolina Oliveira Mesquita ${ }^{1} \oplus$, Fernanda Gabriela Teixeira ${ }^{1}$ Igor Forigo Beloti $^{1} \oplus$, Lara Caroline Borges Moreira Mota ${ }^{1}$, Leandro Jamerson Fonseca ${ }^{1}$, Luciana Alves de Sousa ${ }^{1} \mathbb{D}$, Maria Stella Xavier de Araújo Souza ${ }^{1}$, Nathália Salgado Silva ${ }^{1}$, Nayara Lima Baute Zancan ${ }^{1}$, Tâmara Prado de Morais ${ }^{2} \mathbb{E}$.

${ }^{1}$ LAMIP-ICIAG-UFU, Alunos do Programa de Pós-Graduação em Agronomia, UFU, Universidade Federal de Uberlândia, Instituto de Ciências Agrárias, R. Acre, 1004 - Umuarama, Uberlândia - MG - Brasil, 38405-325; ${ }^{2}$ Pós Doutoranda PNPD- CAPES-UFU, Instituto de Ciências Agrárias, R. Acre, 1004 - Umuarama, Uberlândia - MG - Brasil; ${ }^{3}$ LAMIP-ICIAG-UFU, Professor Titular UFU, Pesquisador - 1 D CNPq, Instituto de ciências Agrárias, R. Acre, 1004 - Umuarama, Uberlândia - MG - Brasil

Endereço para correspondência: Fernando Cezar Juliatti (juliatti@ufu.br)

Data de chegada: 21/01/2018. Aceito para publicação em: 26/11/2018.

\section{RESUMO}

Juliatti, F.C.; Mesquita, A.C.O.; Fernanda Gabriela Teixeira, Beloti, I.F.; Mota, L.C.B.M.; Fonseca, L.J.; Sousa, L.A.; Souza, M.S.X.A.; Silva, N.S.; Zancan, N.L.B.; Morais, T.P.. Caracterização de genótipos de soja com resistência parcial à ferrugem da soja. Summa Phytopathologica, v.45, n.3, p.313-319, 2019.

A ferrugem asiática da soja (FAS), causada pelo fungo Phakopsora pachyrhizi, é uma das doenças mais severas na cultura. Dentre as estratégias para seu manejo propõe-se a utilização de genótipos com resistência horizontal ou parcial, ainda restritos no mercado, mas promissores pela durabilidade da resistência. O objetivo deste trabalho foi avaliar a resistência de diferentes genótipos de soja à ferrugem asiática para futura utilização em programas de melhoramento. Na safra 2015/2016, foram avaliados 11 genótipos de soja provenientes do LAGER-UFU e a cultivar Desafio 8473 (padrão de suscetibilidade) frente à infecção artificial e natural de P. pachyrhizi no campo. Com os dados de severidade da FAS, calculou-se a área abaixo da curva de progresso da doença (AACPD). O percentual de área foliar afetada e os valores da AACPD dos genótipos avaliados oscilaram de 1,56 a 80,75 e de 380,62 a 975,62, respectivamente. Os genótipos L-210, L-166, L-268, L-203, L-279, L-224, L-216 e L-218 apresentam menores valores de AACPD, indicando resistência parcial, enquanto os genótipos L-144, L-104, L-266 e a cv. Desafio 8473 apresentaram maiores valores de AACPD, portanto, com menor resistência parcial ou suscetíveis. Ainda assim, os genótipos L-144, L-104 e L-266 apresentaram coeficientes de progresso da severidade da doença de 1,8 a 2,0 vezes menores comparativamente à cv. Desafio 8473 . Conclui-se que os genótipos do Programa de Melhoramento Genético da UFU (LAGER-UFU), apresentam potencial de utilização no desenvolvimento de cultivares de soja resistentes à P. pachyrhizi.

Palavras-chave: Glycine max (L.) Merrill, Phakopsora pachyrhizi Syd. \& P. Syd, resistência, progresso da doença.

\section{ABSTRACT}

Juliatti, F.C.; Mesquita, A.C.O.; Fernanda Gabriela Teixeira, Beloti, I.F.; Mota, L.C.B.M.; Fonseca, L.J.; Sousa, L.A.; Souza, M.S.X.A.; Silva, N.S.; Zancan, N.L.B.; Morais, T.P.. Characterization of soybean genotypes showing partial resistance to soybean rust. Summa Phytopathologica, v.45, n.3, p.313-319, 2019.

Asian soybean rust (ASR), caused by the fungus Phakopsora pachyrhizi, is one of the most severe diseases that affect the crop. Among management strategies is the use of genotypes with horizontal or partial resistance, which are still restricted in the market but promising due to their resistance durability. The objective of this study was to evaluate the resistance of different genotypes to Asian soybean rust for future use in breeding programs. In the 2015/2016 crop season, 11 soybean genotypes from LAGER-UFU and cv. Desafio8473 (susceptibility pattern) were evaluated for artificial and natural infection by $P$. pachyrhizi in the field. ASR severity data were used to calculate the area under the disease progress curve (AUDPC). The percentage of affected leaf area and the AUDPC values of the evaluated genotypes ranged from 1.56 to $80.75 \%$ and from 380.62 to 975.62 , respectively. The genotypes L-210, L-166, L-268, L-203, L-279, L-224, L-216 and L-218 have lower AUDPC values, indicating partial resistance, while the genotypes L-144, L-104, L-266 and cv. Desafio 8473 showed higher AUDPC values and therefore lower partial resistance or susceptibility. Even so, the genotypes L-144, L-104 and L-266 showed coefficients of disease severity progress 1.8 to 2.0 -fold lower than those of cv. Desafio 8473. In conclusion, the genotypes from UFU Breeding Program (LAGER-UFU) showed potential to be used in the development of soybean cultivars resistant to P. pachyrhizi.

Keywords: Glycine max (L.) Merrill, Phakopsora pachyrhizi Syd. \& P. Syd, resistance, disease progress.

A soja [Glycine $\max$ (L.) Merrill] é cultivada há milhares de anos, com evidências de sua domesticação datando de 7000-6600 a.C. na China (24). Mesmo com a evolução das práticas de cultivo, desde então, a exploração econômica de seu potencial produtivo $(4.000 \mathrm{~kg}$ $\mathrm{ha}^{-1}$ ) dificilmente é alcançada (20), conforme pode ser constatado pelo registro da produtividade média global na safra 2016/2017 equivalente a $2.900 \mathrm{~kg} \mathrm{ha}^{-1}$ (36). Dentre os principais fatores que limitam o rendimento, a lucratividade e o sucesso da produção dessa cultura destacam-se as doenças (20).

A ferrugem asiática da soja (FAS), causada pelo fungo Phakopsora pachyrhizi Syd. \& P. Syd., é uma das doenças mais severas que incidem na cultura, com prejuízos de até $90 \%(15,38)$. Nas Américas, o maior impacto econômico tem sido observado no Brasil, Paraguai e Bolívia, pois o clima nesses países permite ao fungo sobreviver o ano 
todo sem estresse de temperatura ou umidade $(29,39)$. As condições ambientais exercem fundamental importância nas epidemias da FAS. O molhamento foliar contínuo, promovido pelo orvalho ou pela chuva, sob condições ótimas de temperatura $\left(23\right.$ a $\left.29{ }^{\circ} \mathrm{C}\right)$, favorece o rápido desenvolvimento da doença (1), sendo a precipitação pluviométrica total considerada o fator mais importante na severidade final da doença nas condições de campo $(12,29,36,39)$.

Os sintomas podem surgir em qualquer momento do ciclo fenológico da cultura, porém, são mais frequentes em plantas próximas ou em plena floração. Os sintomas são observados principalmente nas folhas baixeiras, com lesões com pústulas de coloração acastanhada a creme que evoluem para manchas necróticas de forma poligonal ou irregulares e anguladas de coloração parda a marrom. Para a diagnose precisa da doença deve-se observar a formação abundante de uredínias na face abaxial das folhas. Estas ocorrem em forma inicial de erupções ou protuberâncias esbranquiçadas e brilhantes que se rompem e liberam os urediniosporos $(2,35,39)$.

As estratégias preconizadas no Brasil para o manejo dessa doença incluem práticas culturais, aplicação de fungicidas e uso de cultivares resistentes. O controle cultural engloba a utilização de cultivares de ciclo precoce e semeadura no início da época recomendada, a eliminação de plantas de soja voluntárias, a ausência de cultivo de soja na entressafra (vazio sanitário) e o monitoramento da doença nas lavouras $(15,16$, 20,21, 25). Pulverizações preventivas e curativas de fungicidas também têm sido amplamente adotadas no controle da FAS $(2,3,14,17,32)$. Entretanto, em virtude da redução da sensibilidade de populações do fungo aos princípios ativos frequentemente utilizados (20), muitos produtos não são mais recomendados pelo Ministério da Agricultura, Pecuária e Abastecimento para o controle dessa doença $(7,28)$.

Em se tratando da obtenção de cultivares de soja resistentes ao patógeno, sete genes dominantes, denominados Rpp 1-7 (8, 11, 13, 16, $18,25,26)$, que condicionam resistência vertical (qualitativa), foram relatados na literatura, mas a estabilidade desse tipo de resistência pode não ser durável quando testada a campo contra distintas populações de P. pachyrhizi (15). Contrapondo-se aos Rpp, a resistência horizontal (quantitativa), conferida por muitos genes de efeitos menores, tem amplo espectro sobre novas raças do patógeno dificultando que este supere a resistência da planta. Esta resistência é caracterizada, principalmente, por reduzir a intensidade da doença no campo $(33,35,36)$. A resistência dos genótipos avaliados foi oriunda do parental IAC 100, tido como portador de outros genes menores diferentes dos Rpps e com efeito na redução na taxa de progresso da doença e na severidade final da doença implicando em menores AACPD $(33,35)$. Alguns autores (27) tem confundido a resistência parcial $(30,33,35)$, envolvendo componentes da resistência como PL(Período latente), PE(período de esporulação), PI (Período de incubação), entre outros, "sensu Parlevliet" (30), com tolerância, que é conceituada como planta suscetível. Nesse caso a planta com tolerância consegue ainda produzir razoavelmente, mas sem redução na área abaixo da curva de progresso da epidemia (AACPD).

Portanto, a identificação de genótipos que possam ser utilizados como fonte para a resistência horizontal $(33,35,27,38)$ "sensu" Parlevliet $(33,35)$ é primordial para aumentar a longevidade das cultivares lançadas no mercado. Esta justificativa norteou o presente trabalho que visou avaliar, dentre as linhagens disponíveis no banco de germoplasma (LAGER-UFU), da Universidade Federal de Uberlândia, genótipos de soja promissores para o manejo genético da FAS com resistência parcial à doença.

\section{MATERIAL E MÉTODOS}

O trabalho foi conduzido em área da Fazenda Experimental do Glória, da Universidade Federal de Uberlândia, localizada a $18^{\circ} 57^{\prime} 15^{\prime}$ 'S, $48^{\circ} 12^{\prime} 41^{\prime \prime} \mathrm{W}$ e altitude de $860 \mathrm{~m}$. A semeadura manual dos genótipos de soja ocorreu no dia 16/12/2015. Na época escolhida de semeadura, as condições climáticas vigentes permitiram para o estabelecimento de microclima favorável ao patógeno e à germinação dos urediniosporos para início do processo infeccioso. As parcelas experimentais foram constituídas por duas linhas úteis de $6 \mathrm{~m}$ de comprimento espaçadas em $0,5 \mathrm{~m}$.

A implantação do experimento foi em delineamento de blocos casualizados com quatro repetições. Foram avaliados 11 genótipos de soja de ciclo médio em trono de 115 dias, provenientes do germoplasma do LAGER-UFU (L-218, L-266, L-144, L-166, L-104, L-203, L-224, L-268, L-210, L-279 e L-216) e a cultivar Desafio 8473 (linhagem comercial BRASMAX), de ciclo precoce (105 dias). As linhagens foram obtidas por cruzamentos entre as cultivares BRS Caiapônia e IAC 100 e selecionadas na geração $\mathrm{F}_{6}$, quando não apresentavam segregação para cor de flor, pubescência e ciclo. Todas as linhagens selecionadas apresentam ciclo variando entre 110-120 dias. A cv. Desafio 8473 foi utilizada como padrão de suscetibilidade após testes preliminares com inoculações artificiais no estádio $\mathrm{V}_{2}$ e condições controladas de incubação $\left(22{ }^{\circ} \mathrm{C}\right.$ e $100 \%$ de umidade relativa $)$.

Para demarcação das extremidades do experimento e das linhas úteis, foram semeadas duas linhas da cultivar comercial MONSOY 7739 RR IPRO, que apresenta características agronômicas de alto vigor e suscetibilidade à FAS. A suscetibilidade desta cultivar ao patógeno contribuiu para maior incidência de inóculo na área.

No estádio reprodutivo da cultura $\left(\mathrm{R}_{1}\right.$ - início da floração), aplicou-se um fungicida à base de azoxistrobina + benzovindiflupyr na dose de $250 \mathrm{~g} \mathrm{ha}^{-1}$, com volume de calda de $200 \mathrm{~L} \mathrm{ha}^{-1}$ para reduzir o progresso de outras doenças e a agressividade da ferrugem da soja (melhor expressão da resistência parcial). Para a aplicação utilizou-se um pulverizador costal motorizado, modelo Yamaho, equipado de barra de $3 \mathrm{~m}$ com pontas XR110.02 pulverizando nos três primeiros metros de cada linha em duas passadas (correspondendo à aplicação de $250 \mathrm{~mL}$ faixa ${ }^{-1}$ por passada). O controle de plantas infestantes nas entrelinhas foi realizado por capina manual. Devido à ocorrência do inseto desfolhador Diabrotica speciosa (Germar, 1824) (Coleoptera: Chrysomelidae) na área experimental, fez-se necessária a aplicação de inseticida piretroide para redução de possíveis danos no limbo foliar que influenciariam diretamente nas avaliações de severidade da ferrugem.

Os dados de temperatura $\left({ }^{\circ} \mathrm{C}\right)$, umidade relativa do ar $(\%)$ e precipitação pluvial $(\mathrm{mm})$ foram obtidos da estação meteorológica do Instituto Nacional de Meteorologia (5), a partir de 30 dias após a semeadura dos genótipos de soja até o final do experimento. Esse período compreendeu a incidência e evolução da doença nas plantas hospedeiras.

No estádio $\mathrm{R}_{1}$ (início do florescimento) foi realizada, em todos os genótipos, uma inoculação de urediniosporos na concentração de 10.000 por $\mathrm{mL}$ de água e Tween 20 a $0,05 \%$.

Durante todo o ciclo da cultura, foram realizadas quatro avaliações de severidade da FAS: aos 51 (01/03/2016), 61 (11/03/2016), 71 $(21 / 03 / 2016)$ e $81(31 / 03 / 2016)$ dias após a semeadura (DAS). As avaliações basearam-se na escala diagramática de Polizel \& Juliatti (31) a qual atribui percentuais de severidade em virtude da área foliar coberta por sintomas da doença. Foram avaliados cinco folíolos e dois trifólios por parcela útil, coletados no terço médio das plantas. Também 
foram utilizadas as variáveis climáticas no local de experimentação, considerando temperatura mínima, máxima, umidade relativa e precipitação pluvial (5).

A partir dos dados de severidade da FAS, calcularam-se a área abaixo da curva de progresso da doença (AACPD) (33) e a taxa de progresso da doença $(r)$ (9). A AACPD é uma variável recomendada por alguns autores por representar a epidemia como um todo, pois leva em consideração o estresse que a cultura sofreu durante vários estádios de desenvolvimento (4). As médias de severidade, AACPD e $r$ foram submetidas à análise de variância e comparadas pelo teste de ScottKnott a 5\% de significância. Para a variável severidade foi realizada regressão polinomial para análise temporal.

\section{RESULTADOS E DISCUSSÃO}

Apesar de originária de regiões temperadas (24), a soja possui ampla aptidão edafoclimática, principalmente decorrente do desenvolvimento de materiais adaptados a condições tropicais e subtropicais. As condições climáticas durante o período experimental foram favoráveis ao desenvolvimento da cultura e também do patógeno, ressaltando que as temperaturas máximas não apresentaram elevações extremas e duradouras (Figura 1). A temperatura variou de 20 a $31{ }^{\circ} \mathrm{C}$ (mínima e máxima registradas, respectivamente), a umidade relativa do ar de 39 a 96\% e a precipitação pluvial acumulada foi de $741 \mathrm{~mm}$ (5). Os dados registrados durante o experimento condizem, portanto, com a faixa de

A

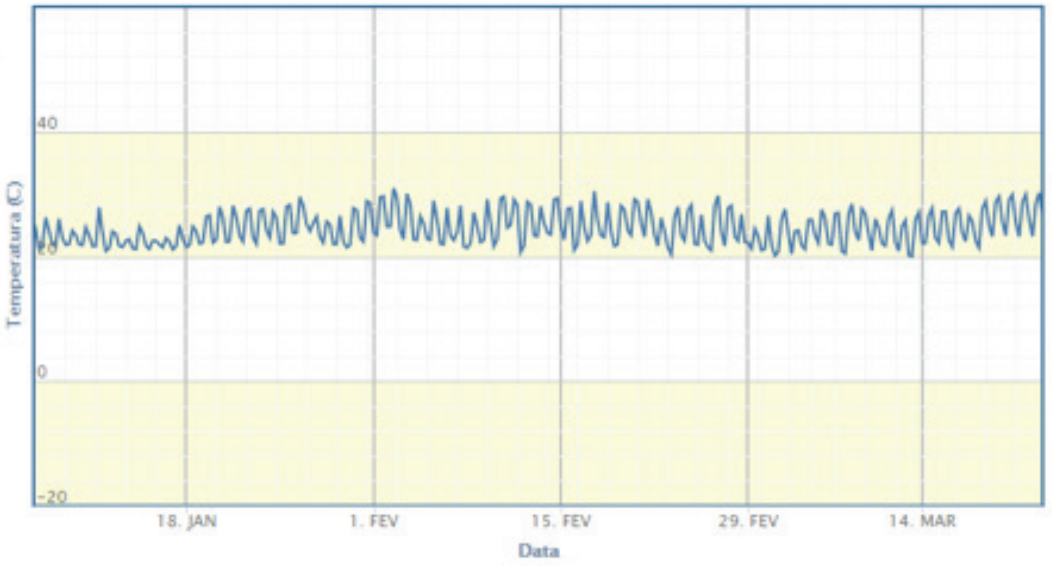

B

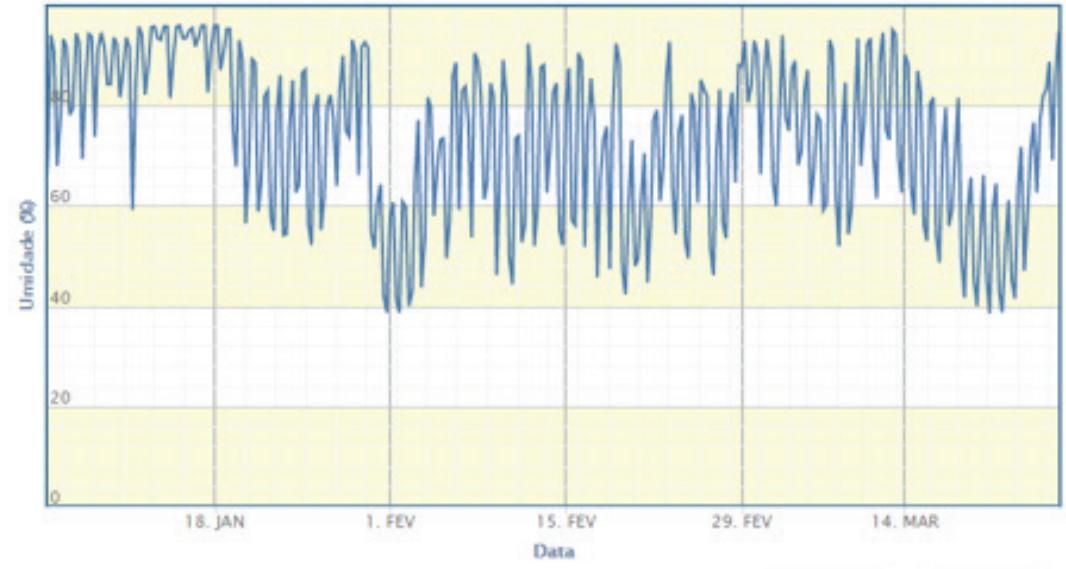

C

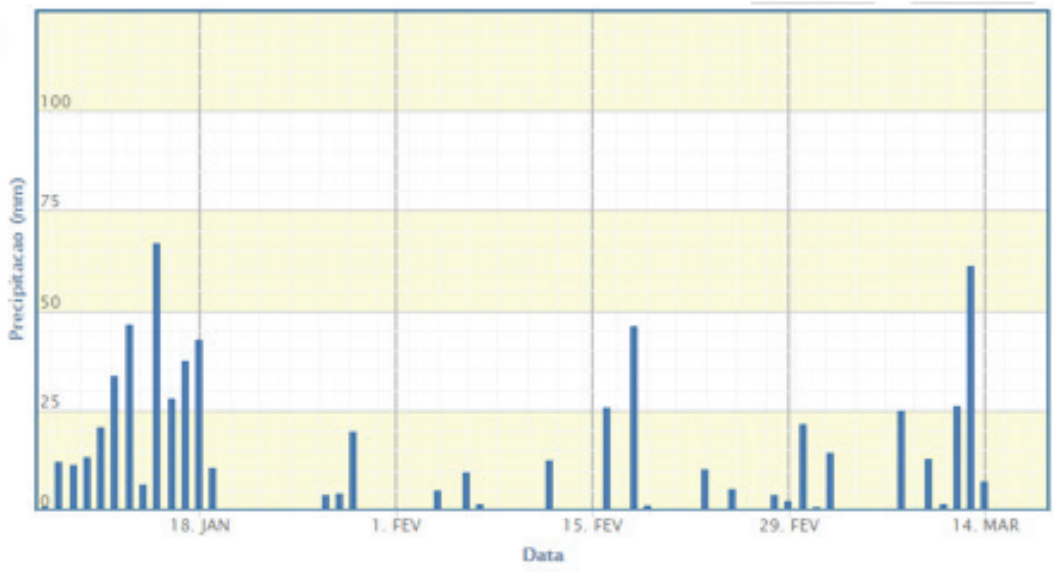

Figura 1. Dados climáticos da Estação Automática A507, Uberlândia-MG. Fonte: INMET, 2016. (A) Temperatura média ( $\left.{ }^{\circ} \mathrm{C}\right)$, (B) Umidade relativa do ar (\%) e (C) Precipitação pluvial ( $\mathrm{mm})$. 
Tabela 1. Severidade da ferrugem asiática (Phakopsora pachyrhizi) da soja em condições de campo. Uberlândia-MG, 2016

\begin{tabular}{lcccc}
\hline \multirow{2}{*}{ Genótipo } & \multicolumn{4}{c}{ Dias após a semeadura (DAS) } \\
\cline { 2 - 5 } & $\mathbf{5 1 *}$ & $\mathbf{6 1 *}$ & $\mathbf{7 1 *}$ & $\mathbf{8 1 *}$ \\
\hline L-218 & $2,62 \mathrm{a}$ & $12,62 \mathrm{a}$ & $20,62 \mathrm{a}$ & $37,0 \mathrm{a}$ \\
L-266 & $10,87 \mathrm{a}$ & $15,75 \mathrm{a}$ & $28,75 \mathrm{~b}$ & $51,0 \mathrm{a}$ \\
L-144 & $5,12 \mathrm{a}$ & $13,87 \mathrm{a}$ & $27,5 \mathrm{~b}$ & $39,25 \mathrm{a}$ \\
L-166 & $3,0 \mathrm{a}$ & $4,87 \mathrm{a}$ & $18,75 \mathrm{a}$ & $38,25 \mathrm{a}$ \\
L-104 & $5,12 \mathrm{a}$ & $13,75 \mathrm{a}$ & $29,37 \mathrm{~b}$ & $44,75 \mathrm{a}$ \\
L-203 & $3,62 \mathrm{a}$ & $7,37 \mathrm{a}$ & $18,12 \mathrm{a}$ & $38,25 \mathrm{a}$ \\
L-224 & $2,75 \mathrm{a}$ & $10,5 \mathrm{a}$ & $20,0 \mathrm{a}$ & $34,25 \mathrm{a}$ \\
L-268 & $1,56 \mathrm{a}$ & $7,87 \mathrm{a}$ & $16,87 \mathrm{a}$ & $40,5 \mathrm{a}$ \\
L-210 & $1,62 \mathrm{a}$ & $5,0 \mathrm{a}$ & $15,0 \mathrm{a}$ & $34,5 \mathrm{a}$ \\
L-279 & $4,25 \mathrm{a}$ & $8,12 \mathrm{a}$ & $15,5 \mathrm{a}$ & $42,25 \mathrm{a}$ \\
L-216 & $2,37 \mathrm{a}$ & $7,25 \mathrm{a}$ & $20,62 \mathrm{a}$ & $45,0 \mathrm{a}$ \\
Desafio 8473 & $4,12 \mathrm{a}$ & $21,37 \mathrm{a}$ & $33,75 \mathrm{~b}$ & $80,75 \mathrm{~b}$ \\
\hline
\end{tabular}

${ }^{1}$ Médias seguidas por letras distintas, na coluna, diferem entre si a 5\% de significância pelo teste de Scott-Knott. *\% da área foliar afetada.

clima recomendada para o cultivo da soja (temperaturas médias entre 20 a $35^{\circ} \mathrm{C}$ e precipitações pluviométricas de 700 a $1.200 \mathrm{~mm}$ ao ano) (1). Semelhantemente, o clima chuvoso durante a infecção promoveu o molhamento foliar e, associado a temperaturas mais amenas (entre 20 e $26^{\circ} \mathrm{C}$ ), favoreceu a infecção e progresso da FAS.

A severidade da ferrugem nos genótipos de soja, via infecção natural e no decorrer das quatro avaliações, correspondeu a percentuais da área foliar afetada de 1,56 a 80,75 (Tabela 1). Diferenças entre os materiais genéticos foram observadas somente a partir da terceira avaliação (aos 71 e 81 DAS), destacando a suscetibilidade da cv. Desafio 8473 à FAS.

Tabela 2. Área abaixo da curva de progresso da doença (AACPD) e taxa de progresso $(r)$ da ferrugem asiática (Phakopsora pachyrhizi) da soja em condições de campo ${ }^{1}$. Uberlândia-MG, 2016

\begin{tabular}{lcc}
\hline Genótipo & AACPD & $r$ \\
\hline L-218 & $530,62 \mathrm{a}$ & $0,097 \mathrm{a}$ \\
L-266 & $754,37 \mathrm{~b}$ & $0,055 \mathrm{a}$ \\
L-144 & $635,62 \mathrm{~b}$ & $0,090 \mathrm{a}$ \\
L-166 & $442,5 \mathrm{a}$ & $0,098 \mathrm{a}$ \\
L-104 & $680,62 \mathrm{~b}$ & $0,082 \mathrm{a}$ \\
L-203 & $464,37 \mathrm{a}$ & $0,088 \mathrm{a}$ \\
L-224 & $490,0 \mathrm{a}$ & $0,104 \mathrm{a}$ \\
L-268 & $457,81 \mathrm{a}$ & $0,111 \mathrm{a}$ \\
L-210 & $380,62 \mathrm{a}$ & $0,129 \mathrm{a}$ \\
L-279 & $468,75 \mathrm{a}$ & $0,110 \mathrm{a}$ \\
L-216 & $515,62 \mathrm{a}$ & $0,119 \mathrm{a}$ \\
Desafio 8473 & $975,62 \mathrm{~b}$ & $0,110 \mathrm{a}$ \\
\hline
\end{tabular}

${ }^{1}$ Médias seguidas por letras distintas, na coluna, diferem entre si a 5\% de significância pelo teste de Scott-Knott.
Aos 71 DAS, os genótipos L-266, L-144 e L-104 apresentaram médias de severidade equiparáveis à da cv. Desafio 8473 (33,75\% da área foliar afetada). Ainda assim, na última avaliação, esses genótipos registraram percentuais estatisticamente iguais à resistência de L-216 (45\%). Variações nas respostas fenotípicas, além do componente genético, podem ser atribuídas à sub ou superestimação dos valores de severidade, em virtude da subjetividade do avaliador em determinar o percentual da área foliar das plantas efetivamente afetada pelo patógeno. Além disso, a distribuição natural e não-homogênea do inóculo de $P$. pachyrhizi na área experimental também pode contribuir para as variações observadas em alguns genótipos entre a terceira e a quarta avaliações, mesmo após uma inoculação artificial e uso do genótipo suscetível MONSOY 7739 na bordadura de cada parcela para multiplicar o patógeno e mitigar essa heterogeneidade de ocorrência.

Os valores médios da área abaixo da curva de progresso da doença (AACPD) dos genótipos variou de 380,62 a 975,62 (Tabela 2). Maiores médias foram registradas para os genótipos L-266, L-144, L-104 e para a cv. Desafio 8473, semelhante ao observado aos 71 DAS quanto à severidade da FAS, conferindo-lhes caráter suscetível. Os demais genótipos foram considerados resistentes parcialmente à $P$. pachyrhizi. Visto a inexistência de parâmetros pré-estabelecidos para classificação da resistência com base nos valores de AACPD, os genótipos foram agrupados com referência aos valores do padrão de suscetibilidade (cv. Desafio 8473). Genótipos com médias estatisticamente iguais ao padrão foram considerados suscetíveis; ao passo que a resistência foi atribuída às médias estatisticamente inferiores às do padrão. A taxa de progresso da doença $(r)(9)$ não permitiu detecção de diferenças entre os genótipos, portanto, não foi um parâmetro adequado para avaliação da resistência parcial entre os genótipos avaliados (Tabela 2). AAACPD foi utilizada por vários pesquisadores para classificar genótipos com resistência parcial à ferrugem da soja por reduzir o progresso da doença $(20,33,35)$ e aumentar o período latente contribuindo para menor reprodução do patógeno, maior área foliar verde e, consequentemente, maior enchimento de grãos, e nesse caso com uma AACPD acima de 900 (quantidade de doença versus tempo).

Conforme evidenciado nas análises de severidade e AACPD, a cv. Desafio 8473 apresentou susceptibilidade à $P$. pachyrhizi. O coeficiente de inclinação linear para essa cultivar $(9,10)$ foi até 2,33 vezes maior que o das equações dos outros genótipos testados (Figura 2), indicando progresso mais acentuado da severidade da doença. $\mathrm{O}$ uso de genótipos de soja precoces (como a cv. Desafio 8473, grupo de maturação 7.4) é uma estratégia recomendada para evitar danos significativos à produtividade da cultura pela incidência da FAS $(20,22,27)$. Essa estratégia baseia-se no princípio da evasão, em que a cultura fica menos tempo no campo reduzindo os danos causados pelo fungo $(20,27,37,38)$. Entretanto, visto os resultados apresentados, essa prática deve ser adotada com cautela pois, em condições de incidência precoce e severa da FAS, a cultivar suscetível terá seu rendimento comprometido e poderá atuar como fonte multiplicadora de inóculo na área.

As análises de regressão polinomial (Figura 2) evidenciaram aumento linear da severidade da FAS ao transcorrer dos tempos de avaliação em todos os materiais genéticos testados. Os valores de $\mathrm{R}^{2}$ oscilaram de 83,7 a 99,3\%, refletindo bom ajuste dos modelos, e os menores coeficientes de inclinação das retas (comparativamente ao da cv. Desafio 8473) indicam redução na evolução da doença. Este resultado é interessante pois a menor proporção de severidade durante o ciclo de desenvolvimento da cultura implicaria menor redução da produtividade.

Para seleção de genótipos promissores, novas avaliações em 

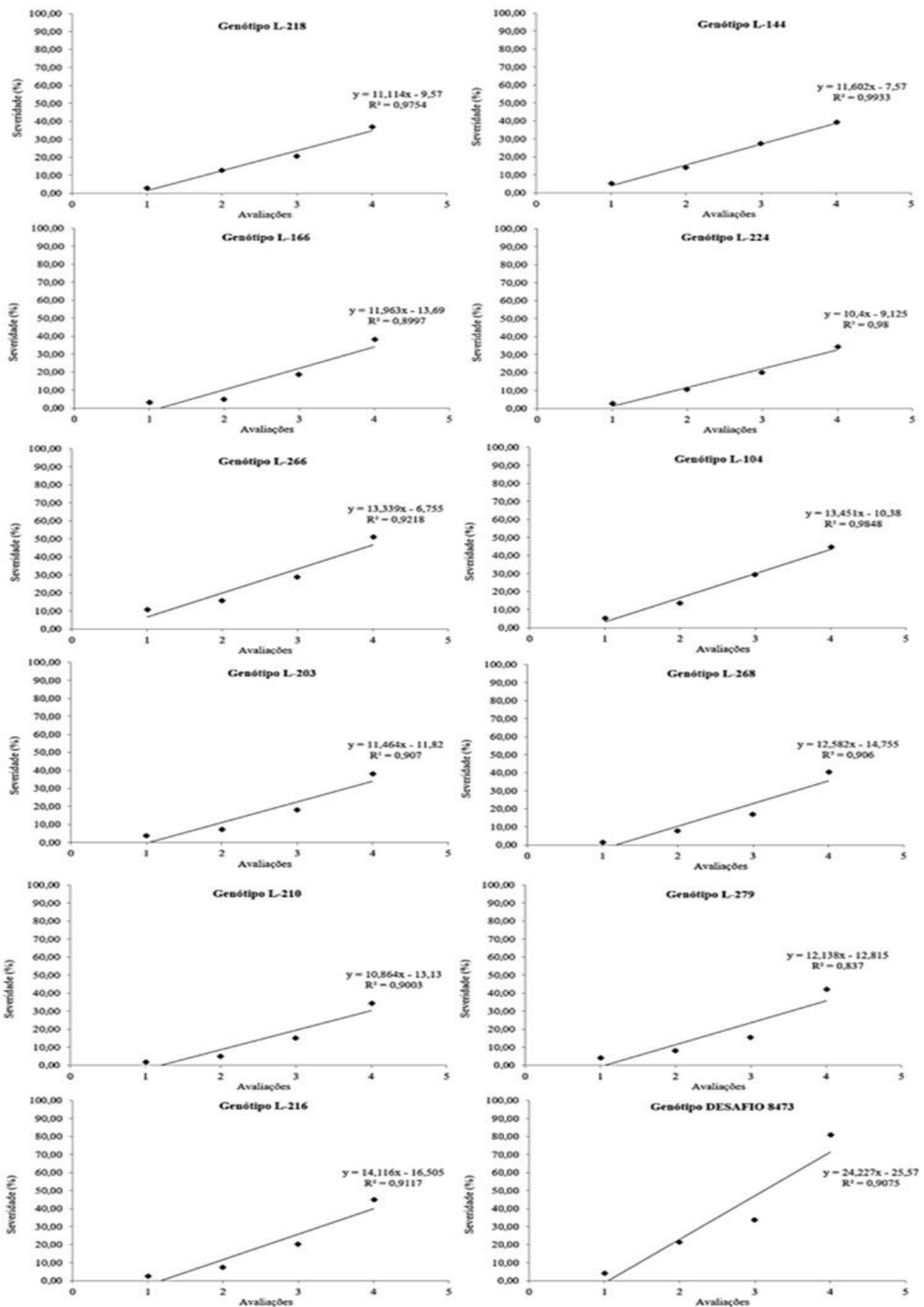

Figura 2. Progresso da severidade da ferrugem asiática (Phakopsora pachyrhizi) em genótipos de soja em condições de campo. Avaliações realizadas a cada dez dias. Uberlândia-MG, 2016. 
diferentes ambientes (locais, safras e épocas de semeadura) devem ser realizadas (10). Um genótipo considerado resistente parcialmente pode apresentar sintomas semelhantes àqueles de um genótipo suscetível, porém receberá menor evolução da doença e menores danos pela infecção. Dessa forma, cultivares resistentes parcialmente podem demandar menor número de aplicações de fungicidas e, assim, contribuir com a redução nos custos de produção da lavoura (30). $\mathrm{Na}$ seleção, deve-se, ainda, considerar a produtividade. Visto isto, mesmo genótipos classificados como suscetíveis (L-266, L-144 e L-104) poderiam, ao final do ciclo, apresentar mínimas reduções em produtividade, o que lhes conferiria níveis de resistência. Todos os genótipos estudados, com exceção da cv. Desafio 8473 e das linhagens L-266, L-144 e L-104, foram resistentes à FAS, pois apresentaram menor severidade da doença e menor AACPD. No entanto, mais estudos devem ser realizados em diferentes ambientes e considerando dados de produtividade para a confirmação dessa resistência. Os resultados obtidos indicam potencial de utilização de genótipos do germoplasma do LAGER-UFU no desenvolvimento de cultivares de soja resistentes à $P$. pachyrhizi, quer seja como parentais de novos cruzamentos ou diretamente como novas cultivares. A arquitetura com pouca ramificação de muitos genótipos com resistência parcial também é uma ferramenta auxiliar importante no manejo da ferrugem da soja, permitindo melhor cobertura dos fungicidas e maiores rendimentos em relação aos genótipos suscetíveis (24).Um exemplo de genótipo com resistência parcial que foi lançado no Brasil foi a cultivar BRSGO 7560 (27). A única maneira de reduzir o uso de fungicidas em campo que no Brasil já atinge em média praticamente 4 pulverizações por safra seria o uso da resistência parcial "sensu Parlevliet" (30) e desse modo o risco de resistência aos fungicidas no campo (21) reduzindo assim o risco dos produtores de soja.

\section{REFERÊNCIAS}

1. Alves, S.A.M.; Furtado, G.Q.; Bergamin Filho, A. Influência das condições climáticas sobre a ferrugem da soja. In: Zambolim, L. Ferrugem asiática da soja. Viçosa: Suprema Gráfica e Editora Ltda, 2006. p.37-59.

2. Azevedo, L.A.S.; Juliatti, F.C.; Balardin, R.S.; Correa, O.S. Programa Syntinela: monitoramento da dispersão de Phakopsora pachyrhizi e alerta contra a ferrugem asiática da soja. Campinas: Emopi Gráfica e Editora, 2004. 24p.

3. Azevedo, L.A.S. Proteção integrada de plantas com fungicidas: teoria, prática e manejo. São Paulo: Editora do Autor, 2001. 230p.

4. Bergamin Filho, A.; Amorim, L. Doenças de plantas tropicais: epidemiologia e controle econômico. São Paulo: Agronômica Ceres, 1996. 289p.

5. Brasil. Instituto Nacional de Meteorologia. Rede de estações: Estação Automática A507 - Uberlândia. 2016. Disponível em: <http://www.inmet.gov. br/portal/index.php?r=estacoes/mapaEstacoes>. Acesso em: 20 jun. 2016.

6. Brasil. Ministério da Agricultura, Pecuária e Abastecimento. Ato no 71 , de 16 de dezembro de 2016. Diário Oficial da União, Brasília, DF, n. 242, p. 14, 19 dez. 2016. Seção 1. Disponível em: <http://pesquisa.in.gov.br/imprensa/ jsp/visualiza/index.jsp?data=19/12/2016\&jornal=1\&pagina=14\&totalArquivos $=152>$. Acesso em: $11 \mathrm{dez} .2017$.

7. Brasil. Ministério da Agricultura, Pecuária e Abastecimento. Ato $n^{\circ} 46$, de 9 de junho de 2017. Diário Oficial da União, Brasília, DF, n. 113, p. 3, 14 jun. 2017. Seção 1. Disponível em: <http://pesquisa.in.gov.br/imprensa/ jsp/visualiza/index.jsp?data $=14 / 06 / 2017 \&$ jornal=1\&pagina $=3 \&$ totalArquivos=176>. Acesso em: $11 \mathrm{dez} .2017$.

8. Bromfield, K.R.; Hartwig, E.E. Resistance to soybean rust (Phakopsora pachyrhizi) and mode of inheritance. Crop Science, Madison, v.20, p.254$255,1980$.

9. Campbell, C.L.; Madden, L.V. Crop loss assessment and modeling. In: Cam€ pbell, C.L.; Madden, L.V. Introduction to plant disease epidemiology. New York: John Wiley \& Sons, 1990. p.393-422.

10. Carvalho, C.G.P.; Arias, C.A.A.; Toledo, J.F.F.; Almeida, L.A.; Kiihl, R.A.S.;
Oliveira, M.F. Interação genótipo x ambiente no desempenho produtivo da soja no Paraná. Pesquisa Agropecuária Brasileira, Brasília, DF, v.37, n.7, p.989-1000, 2002.

11. Childs, S.P.; King, Z.R.; Walker, D.R.; Harris, D.K.; Pedley, K.F.; Buck, J.W.; Boerma, H.R.; Li, Z. Discovery of a seventh Rpp soybean rust resistance locus in soybean accession PI 605823. Theoretical and Applied Genetics, Berlin, v.131, n.1, p.27-41, 2018.

12. Del Ponte, E.M.; Godoy, C.V.; Li, X.; Yang, X.B. Predicting severity of Asian soybean rust epidemics with empirical rainfall models. Phytopathology, Saint Paul, v.96, p.797-803, 2006.

13. Garcia, A.; Calvo, E.S.; Kiihl, R.A.S.; Harada, A.; Hiromoto, D.M.; Vieira, L.G.E. Molecular mapping of soybean rust (Phakopsora pachyrhizi) resistance genes: discovery of a novel locus and alleles. Theoretical and Applied Genetics, Berlin, v.117, p.545-553, 2008.

14. Godoy, C.V. Phakopsora pachyrhizi: the performance of soybean rust fungicides over years and regions in Brazil. In: Dehne, H.W.; Deising, H.B.; Gisi, U.; Kuck, K.H.; Russell, P.E.; Lyr, H. Modern Fungicides and Antifungal Compounds. 6th ed. Braunschweig: Deutsche Phytomedizinische Gesellschaft e.V. Selbstverlag, 2011. p.203-209.

15. Godoy, C.V.; Seixas, C.D.S.; Soares, R.M.; Marcelino-Guimarães, F.C.; Meyer, M.C.; Costamilan, L.M. Asian soybean rust in Brazil: past, present, and future. Pesquisa Agropecuária Brasileira, Brasília, DF, v.51, p. 407-421, 2016.

16. Hartman, G.L.; Miles, M.R.; Frederick, R.D. Breeding for resistance to soybean rust. Plant Disease, Saint Paul, v.89, p.664-665, 2005.

17. Hartman, G.L.; Wang, T.C.; Tchanz, A.T. Soybean rust development and the quantitative relationship between rust severity and soybean yield. Plant Disease, Saint Paul, v.75, p.596-600, 1991.

18. Hartwig, E.E.; Bromfield, K.R. Relationships among three genes conferring specific resistance to rust in soybeans. Crop Science, Madison, v.23, p.237-239, 1983.

19. Hartwig, E.E. Identification of a fourth major gene conferring resistance to soybean rust. Crop Science, Madison, v.26, p.1135-136, 1986

20. Juliatti, F.C.; Polizel, C.A.; Juliatti, F.C. Manejo integrado de doenças na cultura da soja. Uberlândia: EDUFU, 2004. 327p.

21. Juliatti, F.C.; Polloni, L.C.; Morais, T.P.; Zacarias, N.R.S.; Silva, E.A.; Juliatti, B.C.M. Sensitivity of Phakopsora pachyrhizi populations to dithiocarbamate, chloronitrile, triazole, strobilurin, and carboxamide fungicides. Bioscience Journal, Uberlândia, v.33, n.4, p.933-943, 2017.

22. Kawuki, R.S.; Tukamuhabwa, P.; Adipala, E. Soybean rust severity, rate of rust development and tolerance as influenced by maturity period and season. Crop Protection, Guildford, v.23, p.447-455, 2004.

23. Kendrick, M.D.; Harris, D.K.; Ha, B.-K.; Hyten, D.L.; Cregan, P.B.; Frederick, R.D.; Boerma, H.R.; Pedley, K.F. Identification of a second Asian soybean rust resistance gene in Hyuuga soybean. Phytopathology, Saint Paul, v.101, p.535-543, 2011.

24. Lee, G.-A.; Crawford, G.W.; Liu, L.; Sasaki, Y.; Chen, X. Archaeological soybean (Glycine max) in East Asia: does size matter? PLoS ONE, [S. 1], v.6, n.11, p.1-12, 2011.

25. Li, S.; Smith, J.R.; Ray, J.D.; Frederick, R.D. Identification of a new soybean rust resistance gene in PI 567102B. Theoretical and Applied Genetics, Berlin, v.125, p.133-142, 2012.

26. McLean, R.J.; Byth, D.E. Inheritance of resistance to rust (Phakopsora pachyrhizi) in soybeans. Australian Journal of Agricultural Research, Victoria, v.31, p.951-956, 1980.

27. Melo, C.L.P.; Roese, A.D.; Goulart, A.C.P. Tolerância de genótipos de soja à ferrugem-asiática. Ciência Rural, Santa Maria, v.45, n.8, p.1353-1360, 2015.

28. Nascimento, J.M.; Gavassoni, W.L.; Bacchi, L.M.A.; Oliveira, J.L.; Laborde, M.C.; Pontim, B.C.A.; Mendes, M.P. Manejo da ferrugem asiática da soja com aplicações de fungicidas iniciadas na detecção do patógeno ou posteriores. Revista Agrarian, Dourados, v.11, p.42-49, 2018.

29. Pivonia, S.; Yang, X.B. Assessment of the potential year-round establishment of soybean rust throughout the world. Plant Disease, Saint Paul, v.88, p.523-529, 2004.

30. Parlevliet J.E. Components of resistance that reduce the rate of epidemic development. Annual Review of Phytopathology 17: 203-222,1979.

31. Polizel, A.C.; Juliatti, F.C. Quantificação de doenças foliares da soja por escalas diagramáticas. Enciclopédia Biosfera, Goiânia, v.6, n.11, p.1-9, 2010.

32. Rosa, C.R.E.; Spehar, C.R.; Liu, J.Q. Asian soybean rust resistance: an overview. Journal of Plant Pathology and Microbiology, Los Angeles, 
v.6, p.1-7, 2015.

33. Santos, J.A.; Juliatti, F.C.; Santos, V.A.; Polizel, A.C.; Juliatti, F.C.; Hamawaki, O.T. Caracteres epidemiológicos e uso da análise de agrupamento para resistência parcial à ferrugem da soja. Pesquisa Agropecuária Brasileira, Brasília, DF, v.42, n.3, p.443-447, 2007.

34. Shaner, G.; Finney, R. The effect of nitrogen fertilization on the expression of slow-mildewing resistance in Knox wheat. Phytopathology, Saint Paul, v.67, n.8, p.1051-1056, 1977.

35. Silva, V.A.S.; Juliatti, F.C.; Silva, L.A.S. Interação entre resistência genética parcial e fungicidas no controle da ferrugem asiática da soja. Pesquisa Agropecuária Brasileira, Brasília, DF, v.42, n.9, p.1261-1268, 2007.

36. Tsukahara, R.Y.; Hikishima, M.; Canteri, M.G. Relações entre o clima e o progresso da ferrugem asiática (Phakopsora pachyrhizi) em duas micro-regiões do Estado do Paraná. Semina: Ciências Agrárias, Londrina, v.29, p.47-52, 2008.

37. United States Department of Agriculture. PS\&D: production, supply, and distribution.2017. Disponível em: <https://apps.fas.usda.gov/psdonline/ app/index.html\#/app/home>. Acesso em: 11 dez. 2017.

38. Yorinori, J.T.; Paiva, W.M.; Costamilan, L.M.; Bertagnolli, P.F. Ferrugem da soja: identificação e controle. Londrina: Embrapa Soja, 2003. 25p.

39. Yorinori, J.T.; Paiva, W.M.; Frederick, R.D.; Costamilan, L.M.; Bertagnolli, P.F.; Hartman, G.E.; Godoy, C.V.; Nunes Junior, J. Epidemics of soybean rust (Phakopsora pachyrhizi) in Brazil and Paraguay. Plant Disease, Saint Paul, v.89, p.675-677, 2005. 